\title{
Study on the Dissolution and Precipitation Behavior of Self-Designed (NbTi)C Nanoparticles Addition in 1045 Steel
}

\author{
Hongwei Zhu ${ }^{1}\left(\right.$, Haonan $\mathrm{Li}^{2}$, Furen $\mathrm{Xiao}^{2, *}$ and Zhixiang Gao ${ }^{1, *}$ \\ 1 College of Physics \& Electronic Science, Shanxi Datong University, Datong 037009, Shanxi, China; \\ hwzhu@stumail.ysu.edu.cn \\ 2 Key Lab of Metastable Materials Science \& Technology and College of Materials Science \& Engineering, \\ Yanshan University, Qinhuangdao 066004, Hebei, China; lihaonan@stumail.ysu.edu.cn \\ * Correspondence: frxiao@ysu.edu.cn (F.X.); gao_zhixiang@126.com (Z.G.); Tel./Fax: +86-335-8077110 (F.X.); \\ Fax: +86-335-80771103 (Z.G.)
}

Citation: Zhu, H.; Li, H.; Xiao, F.; Gao, Z. Study on the Dissolution and Precipitation Behavior of SelfDesigned (NbTi)C Nanoparticles Addition in 1045 Steel. Metals 2021, 11, 184. https://doi.org/10.3390/ met11020184

Academic Editor: Karel Michalek Received: 13 December 2020

Accepted: 15 January 2021

Published: 20 January 2021

Publisher's Note: MDPI stays neutral with regard to jurisdictional claims in published maps and institutional affiliations.

Copyright: (c) 2021 by the authors. Licensee MDPI, Basel, Switzerland. This article is an open access article distributed under the terms and conditions of the Creative Commons Attribution (CC BY) license (https:// creativecommons.org/licenses/by/ $4.0 /)$.

\begin{abstract}
Self-designed (NbTi)C nanoparticles were obtained by mechanical alloying, predispersed in Fe powder, and then added to 1045 steel to obtain modified cast steels. The microstructure of cast steels was investigated by an optical microscope, scanning electron microscope, X-ray diffraction, and a transmission electron microscope. The results showed that $(\mathrm{NbTi}) \mathrm{C}$ particles can be added to steels and occur in the following forms: original ellipsoidal morphology nanoparticles with uniform dispersion in the matrix, cuboidal nanoparticles in the grain, and microparticles in the grain boundary. Calculations by Thermo-Calc software and solubility formula show that cuboidal (NbTi)C nanoparticles were precipitated in the grain, while the (NbTi)C microparticles were formed by eutectic transformation. The results of the tensile strength of steels show that the strength of modified steels increased and then declined with the increase in the addition amount. When the addition amount was $0.16 \mathrm{wt} . \%$, the modified steel obtained the maximum tensile strength of $759.0 \mathrm{MPa}$, which is an increase of $52 \%$ compared with to that with no addition. The hardness of the modified steel increased with the addition of ( $\mathrm{NbTi}) \mathrm{C}$ nanoparticles. The performance increase was mainly related to grain refinement and the particle strengthening of $(\mathrm{NbTi}) \mathrm{C}$ nanoparticles, and the performance degradation was related to the increase in eutectic $(\mathrm{NbTi}) \mathrm{C}$.
\end{abstract}

Keywords: (NbTi)C nanoparticles; microstructure; hardness; strength

\section{Introduction}

There are several ways of preventing failure and prolonging the life of cast steels. Among them, improving the mechanical properties of the material, especially the strength and toughness, is crucial from the perspective of metallurgy [1,2]. One of the effective means to achieve this point is to add fine and well-dispersed ceramic particles to the cast steel to refine the microstructure [3,4]. In addition, the dispersed particles themselves can be used as strengthening particles to further affect the mechanical properties of the cast steels $[5,6]$. Therefore, the particles used as modifiers generally have a high thermal stability, high melting point, high elastic modulus, and are nano-sized. For this reason, $\mathrm{TiC}, \mathrm{NbC}$, TiCN, and other nanoparticles are often used as agents to be added to carbon steels [7-10]. The results of related research show that nanoparticles can become effective nucleation cores, resulting in significant grain refinement and crystal morphology alteration, thereby obtaining modified steel with excellent mechanical properties [10].

Studies have confirmed that the refinement mechanism of the added particles in cast steels occurs when the steel is melted, and the particles are quickly dispersed in the melt [10]. Because of the low concentration of elements such as $\mathrm{Nb}$ or $\mathrm{Ti}$ in the molten metal, the surface of the particles dissolves, which leads to an increase in the concentration of these elements in the local chemical composition of the molten metal, and concentration fluctuations are formed in the close vicinity of the particles during the cooling process [11]. 
As a result, the concentration overcooling in the adsorption layer is formed. Only those active particles with a density close to the melt and stable enough during the crystallization process can become nucleation cores [12].

$\mathrm{NbC}$ and $\mathrm{TiC}$ are undoubtedly good choices as refiners, and much research has been carried out in this field. Qin et al. reported that $\mathrm{NbC}$ can be uniformly distributed in 1020 steel, and the modified steel has improved mechanical properties $[11,13]$. Lazarova et al. reported enhanced mechanical properties of P265GH steel through the dispersion of TiCN particles, and a strengthened aluminum alloy material was also obtained by this method $[12,14]$. Park et al. conducted a series of studies on SA-106B carbon steel reinforced with TiC nanoparticles [15-19]. The results showed that TiC can be evenly dispersed in steel and can obtain improved steel including an increase in the cavitation erosion resistance. In addition, the introduced $\mathrm{TiC}$ nanoparticles were dissolved during hot rolling and reprecipitated vigorously during the normalizing treatment. On the basis of these successful experiences, it is more constructive to use $(\mathrm{NbTi}) \mathrm{C}$ particles with a density close to that of molten steel as a refiner, using the fact that that $\mathrm{NbC}$ and $\mathrm{TiC}$ are both face-centered cubic structures and can be doped with each other.

Most previous studies, however, focused simply on the final microstructure and mechanical properties of the steels added with nanoparticles. Although their performances have been improved, there has been relatively little research conducted on the detailed microstructural evolution during the fabrication schedule $[20,21]$. Therefore, on the basis of previous investigations [22,23], a study on 1045 steel combined with $(\mathrm{NbTi}) \mathrm{C}$ nanoparticles was carried out which aimed at exploring the dissolution and precipitation behaviors of $(\mathrm{NbTi}) \mathrm{C}$ nanoparticles in steel and analyzing the microstructure and mechanical properties of the modified steel.

\section{Materials and Methods}

\section{1. (NbTi)C Particles Preparations and Smelting Test}

(NbTi)C nanoparticles were synthesized by $\mathrm{Nb}$ powder, Ti powder, and graphite powder using a planetary high-energy ball milling machine (BXQM-4L, Telunxin Instrument Co., Ltd, Nanjing, China) and a vacuum annealing process. The raw morphology of the powder, the preparation method, including the technology and process, were elaborated in a previous article [22]. The preparation process is molar ratio $\mathrm{Nb}: \mathrm{Ti}=8: 2-$ mixed ball milling for $2 \mathrm{~h}$, graphite with $(\mathrm{Nb}+\mathrm{Ti}): \mathrm{C}=1: 1$-mixed ball milling for $6 \mathrm{~h}$, then the mixed powder is put into a vacuum tube furnace and annealed at $750{ }^{\circ} \mathrm{C}$ for $30 \mathrm{~min}$ to obtain $(\mathrm{NbTi}) \mathrm{C}$ nanoparticles. Thereafter, the process involves Fe powder with $\mathrm{Fe}:(\mathrm{Nb}+\mathrm{Ti}+\mathrm{C})=$ 1:1-mixed ball milling for $3 \mathrm{~h}$ to obtain predispersion particles. The 1045 steels modified with (NbTi)C nanoparticles were prepared in a vacuum inducting melting and casting furnace and melted in a $\mathrm{MgO}$ crucible with a vacuum of $1.0 \times 10^{-3} \mathrm{~Pa}$. The melt was then smelted and mechanically agitated at $1580-1620^{\circ} \mathrm{C}$ for $2 \mathrm{~min}$. After smelting, the cast ingots of $\varnothing 50 \mathrm{~mm} \times 40 \mathrm{~mm}$ were obtained by pouring molten steel into alumina mold and air cooling to room temperature under the same cooling conditions. Four cast 1045-steel ingots with 0 wt. $\%, 0.13$ wt. $\%, 0.16$ wt. $\%$, and 0.66 wt. $\%$ (NbTi)C nanoparticles were named steel A, B, C and D, respectively. The size of each test steel specimen was $10 \times 10 \times 10 \mathrm{~mm}$, and the chemical compositions are shown in Table 1, which was measured by a SPECTRO MAXx (LMX07)(Germany) direct-reading spectrometer.

Table 1. Chemical compositions of the test steels (wt. \%).

\begin{tabular}{ccccccccc}
\hline Grade & $\mathbf{C}$ & $\mathbf{S i}$ & $\mathbf{M n}$ & $\mathbf{N b}$ & $\mathbf{T i}$ & $\mathbf{P}$ & $\mathbf{S}$ & $\mathbf{F e}$ \\
\hline A & 0.40 & 0.27 & 0.50 & - & - & 0.01 & 0.01 & Bal. \\
B & 0.40 & 0.27 & 0.51 & 0.08 & 0.02 & 0.01 & 0.01 & Bal. \\
C & 0.40 & 0.27 & 0.51 & 0.11 & 0.03 & 0.01 & 0.01 & Bal. \\
D & 0.40 & 0.27 & 0.50 & 0.47 & 0.12 & 0.01 & 0.01 & Bal. \\
\hline
\end{tabular}




\subsection{Microstructure Characterization and Mechanical Property Test}

The phase composition was analyzed using AD/MAX-2500/PC X-ray diffractometer (XRD) with $\mathrm{Cu}-\mathrm{K} \alpha$ (Rigaku Corporation, Akishima, Japan). Specimens were continuously scanned from $20^{\circ}$ to $90^{\circ}$, and the scanning speed was $2^{\circ} / \mathrm{min}$. The microstructure of carbide particles was characterized by S4800 type scanning electron microscopy (SEM)(Hitachi, Japan) with an energy dispersive x-ray detector (EDX) spectrometer and electron backscattered diffraction (EBSD) detector. The acceleration voltage was $20 \mathrm{kV}$, and the resolution of the probe was $129 \mathrm{eV}$. The micrographs including selected-area diffraction pattern (SADP) were obtained by a FEI Tecnai G2 F30 (Hillsboro, OR, USA) transmission electron microscopy (TEM) at $300 \mathrm{kV}$. The specimens for EBSD were sliced by wire electrical discharge machining (WEDM)(Lingfeng, China) to a thickness of $700 \mu \mathrm{m}$ and then polished using 150 to 2000 grit $\mathrm{SiC}$ paper to a thickness of $280 \mu \mathrm{m}$. The specimens for TEM were made using the same method, but they were sliced at $500 \mu \mathrm{m}$ and polished by $\mathrm{SiC}$ paper to a thickness of $30 \mu \mathrm{m}$. All the samples used a twin-jet polisher in a $7 \mathrm{vol} \%$ acid and $93 \mathrm{vol} \%$ glacial acetic acid. The electrolytic voltage was $24 \mathrm{~V}$, and the light flux was 20 . The crystalline grain and orientation of the four steels were analyzed by EBSD with a step size of $0.2 \mu \mathrm{m}$. For the study of carbides in steel D, the sample was cut into three small squares of $3 \times 3 \times 3 \mathrm{~mm}$ by a wire electrical discharge machining. The samples were placed in hydrochloric acid and heated in a water bath for $10 \mathrm{~h}$ at $70{ }^{\circ} \mathrm{C}$. A $5 \mathrm{~mL}$ sample solution was taken, enough $\mathrm{NaHCO}_{3}$ was added to neutralize the solution, and it was centrifuged in an H1650 centrifuge at 10,000 r/min for $5 \mathrm{~min}$. The sediment was taken out for SEM mapping analysis.

\subsection{Mechanical Properties Test}

The hardness of the test steels was characterized by a microhardness test by employing on a FM-ARS 9000 (Mitutoyo Corporation, Kawasaki, Japan) full-automatic microhardness tester. The Vickers hardness was measured with a load $500 \mathrm{gf}$ and a retention time of $15 \mathrm{~s}$, and nine points were taken for each sample. The Rockwell hardness was tested by HR-150A (Huayin, China), and four points were taken for each sample. The tensile test was measured at room temperature with an INSPEKT-100 (Hegewald \& Peschke, Germany) test machine at a stretching speed of $0.5 \mathrm{~mm} / \mathrm{min}$. The parameters of the mechanical performance test are described in detail in a previous article [22].

Thermo-Calc 4.0 software (access date 20 December 2018) was used to calculate the solubility curve of (NbTi)C nanoparticles from $500{ }^{\circ} \mathrm{C}$ to $1600{ }^{\circ} \mathrm{C}$ based on TCFE 7 database, and the dissolution and precipitation behaviors were analyzed theoretically.

\section{Results}

Figure 1a is the SEM micrograph of the powder after $\mathrm{Nb}, \mathrm{Ti}$, and the graphite-mixed ball milling for $8 \mathrm{~h}$ and being heat treated at $750{ }^{\circ} \mathrm{C}$. The size of the powder is about $200 \mathrm{~nm}$ and is ellipsoidal. The (NbTi)C nanoparticles and Fe powder were mixed and mechanically ball-milled for $3 \mathrm{~h}$ to ensure the $(\mathrm{NbTi}) \mathrm{C}$ nanoparticles were uniformly dispersed in the $\mathrm{Fe}$ powder (Figure $1 b$ ). Figure $1 c$ shows the XRD results of the two powders in Figure $1 \mathrm{a}, \mathrm{b}$. The black and red line is the XRD curve of $(\mathrm{NbTi}) \mathrm{C}$ in Figure 1a,b, respectively. The XRD curve of red line shows that the composite powder is composed of two phases, namely $\alpha$-Fe and (NbTi)C. The EDS result of spot 1 in Figure $1 \mathrm{~b}$ is shown in Figure $1 \mathrm{~d}$. It shows that the $(\mathrm{NbTi}) \mathrm{C}$ nanoparticles are evenly embedded in Fe powder, and the mass percentage of the Fe element is 48.9 at.\%, which is close to the theoretical value. 

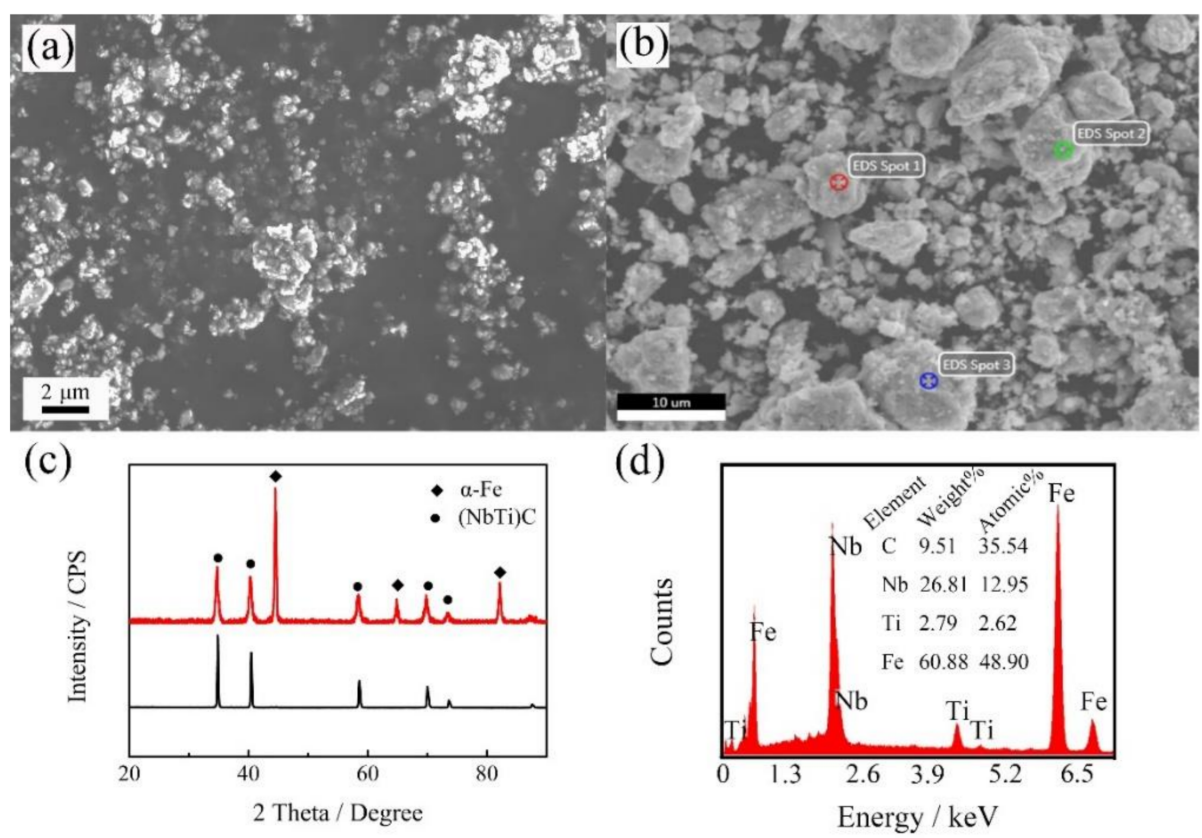

Figure 1. (a) SEM morphology of (NbTi)C; (b) SEM morphology of (NbTi)C / Fe particles; (c) XRD patterns of powder from Figure 1a black line and Figure 1b red line; (d) EDS result of spot 1 in Figure $1 b$.

Figure 2 shows the SEM micrographs of the four steels. It can be seen from the figure that as the content of $(\mathrm{NbTi}) \mathrm{C}$ nanoparticles increased, the number of particles distributed along the prior austenite grain boundaries increased, showing large-sized rods or dots (red dotted marks on Figure 2b-d). The microstructure of steel A was composed of ferrite and pearlite. According to the semi-quantitative calculation method of Image-Pro Plus 6.0, the amount of ferrite in steel A, B, C, and D was $10.47 \%, 38.26 \%, 26.24 \%$, and $37.66 \%$, respectively. After adding the (NbTi)C nanoparticles, the volume fraction of ferrite increased to varying degrees. In addition, it also caused different degrees of degradation of pearlite. In steel D, the clusters of pearlite were divided by the massive ferrite, and the cementite flakes were gradually transformed into short rods or dots. At the same time, with the increase in $(\mathrm{NbTi}) \mathrm{C}$ nanoparticles, ferrite was not only formed in the prior austenite grain boundaries, but also between the pearlite clusters.

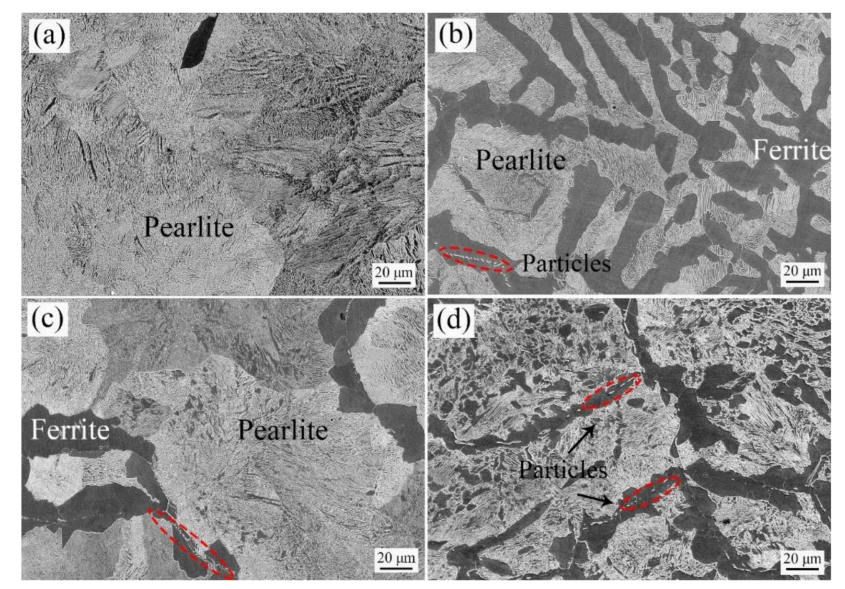

Figure 2. SEM micrographs of the cast steels with different (NbTi)C nanoparticles additions: (a) 0 wt.\%; (b) 0.13 wt.\%; (c) 0.16 wt.\%; (d) 0.66 wt.\%, respectively. 
The EBSD maps of the four steels are shown in Figure 3. It can be seen from the image quality (IQ) maps that the microstructure was significantly refined after adding $(\mathrm{NbTi}) \mathrm{C}$ nanoparticles. The average grain diameters of the test steels were about $16.3,12.8$, 11.3 , and $10.0 \mu \mathrm{m}$, respectively, which indicates that the average grain diameter decreased with the increase in ( $\mathrm{NbTi}) \mathrm{C}$ nanoparticles. In addition, after the addition of $(\mathrm{NbTi}) \mathrm{C}$ nanoparticles, the standard deviation also decreased, and the values were 31.8, 24.0, 24.2, and 21.6, respectively. Thus, it can be seen that (NbTi)C nanoparticles not only refine the grain diameters but also make the grain size more uniform.

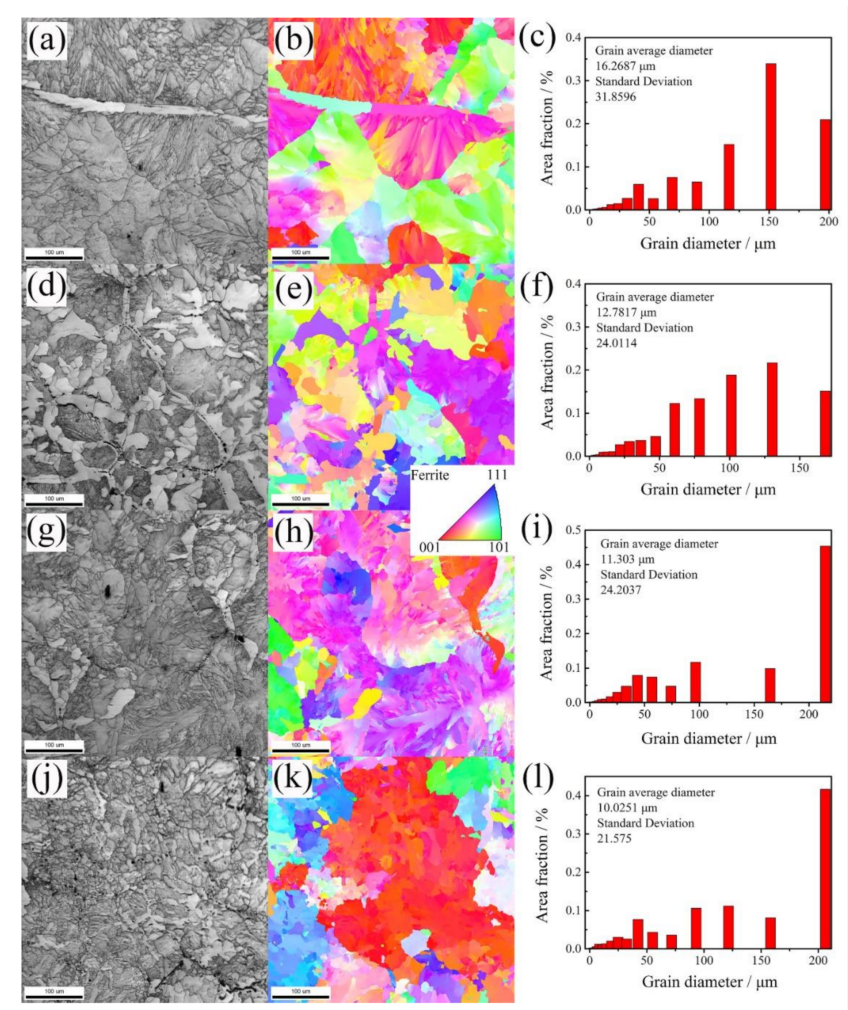

Figure 3. Image quality (IQ) map, inverse pole figure (IPF), and grain diameter statistic. (a-c) for steel A; $(\mathbf{d}-\mathbf{f})$ for steel B; $(\mathbf{g}-\mathbf{i})$ for steel $C ;(\mathbf{j}-\mathbf{l})$ for steel D; respectively. steel D.

Figure 4 shows the different morphologies of $(\mathrm{NbTi}) \mathrm{C}$ nanoparticles observed in
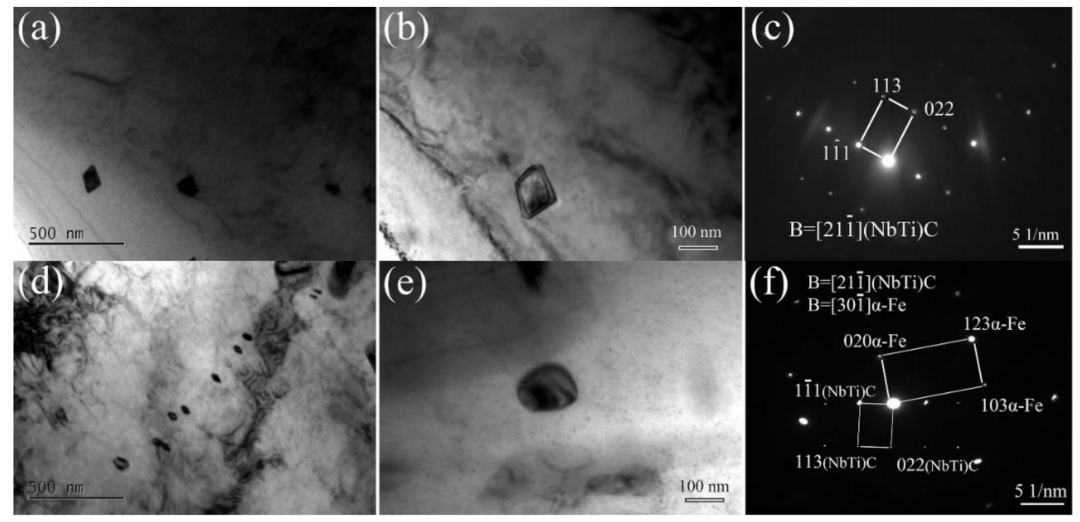

Figure 4. TEM images of cast steel D: $(\mathbf{a}, \mathbf{b})$ precipitated particles; (c) selected-area diffraction pattern (SADP) of square particles in (b); (d,e) added particles; (f) the SADP of the elliptical particle in (e). 
Among them, $(\mathrm{NbTi}) \mathrm{C}$ in Figure $4 \mathrm{a}$ is cuboidal, and in Figure $4 \mathrm{~d}$, it is ellipsoidal. Figure $4 b$,e is partial enlarged views of Figure $4 a, d$, and Figure $4 c, f$ are their SADPs, respectively. After measurement, the cuboidal $(\mathrm{NbTi}) \mathrm{C}$ nanoparticles are about $100 \mathrm{~nm}$; the ellipsoidal (NbTi)C nanoparticles are arranged as linear shape and are about $150 \mathrm{~nm}$. By indexing the diffraction patterns, the zone axis of $(\mathrm{NbTi}) \mathrm{C}$ nanoparticles is $\mathrm{B}=[21-1]$, and that of $\alpha$-Fe is $B=[30-1]$.

Figure 5 is the mapping images of carbides obtained by corrosion centrifugation with steel D as raw material. Obviously, the morphology of these particles was different from the added $(\mathrm{NbTi}) \mathrm{C}$ nanoparticles. The size was on the micrometer level and they presented as irregular polygons. According to the EDS analysis, the particles were mainly composed of $\mathrm{Nb}$ and Ti elements with an atomic ratio of about 7.08:2.27, which is also different from the ratio of $\mathrm{Nb}$ and $\mathrm{Ti}$ in added $(\mathrm{NbTi}) \mathrm{C}$ nanoparticles.

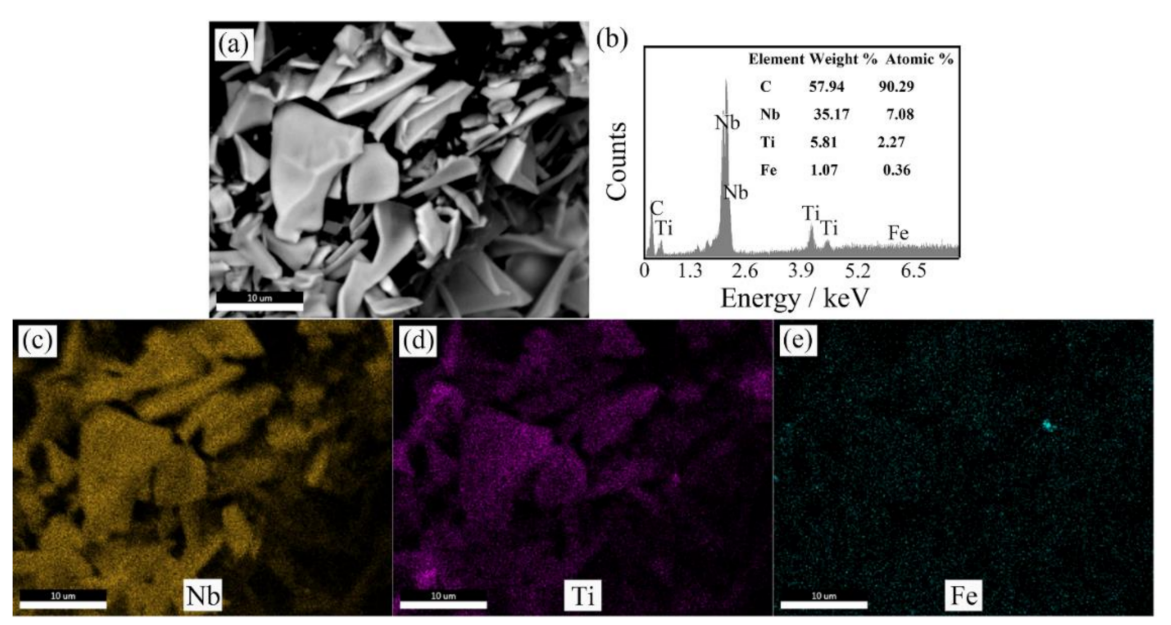

Figure 5. SEM mapping image of precipitate in sample D; (a) micromorphology; (b) the corresponding EDS spectra in (a); (c-e) the microstructural distribution of $\mathrm{Nb}$ (yellow); $\mathrm{Ti}$ (purple); $\mathrm{Fe}(\mathrm{blue})$; respectively.

Figure 6 shows the solubility curve for (NbTi)C at $500-1600{ }^{\circ} \mathrm{C}$, which was simulated using Thermo-Calc software based on the TCFE 7 database. The curve shows that as the temperature increased, (NbTi)C gradually dissolved. For steels $\mathrm{B}, \mathrm{C}$, and $\mathrm{D}$, the total dissolution temperatures of $(\mathrm{NbTi}) \mathrm{C}$ were $1394.9,1410.9$, and $1447.2{ }^{\circ} \mathrm{C}$, respectively. It is worth noting that for the $(\mathrm{NbTi}) \mathrm{C}$ nanoparticles in steel $\mathrm{D}$, a sharp dissolution occurred above $1427.3^{\circ} \mathrm{C}$. At this temperature, the content of $(\mathrm{NbTi}) \mathrm{C}$ dissolved in steel was about 0.25 wt. $\%$.

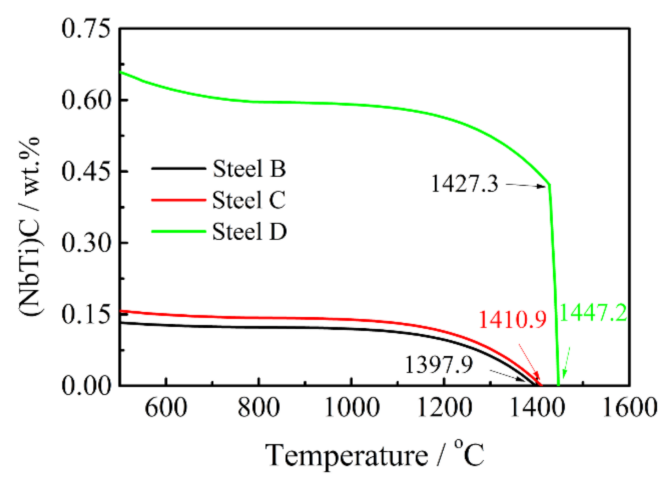

Figure 6. Different additions of (NbTi)C particles dissolution behavior in cast steels using ThermoCalc software based on the TCFE 7 database. 
The mechanical properties of the test steels are shown in Figure 7. Figure 7a shows the engineering strain-stress curve of the test steels. The results show that the yield strength increased with the increase in (NbTi)C content, from 314 to $540.8 \mathrm{MPa}$, with an increase of $72.2 \%$; the tensile strength first increased and then decreased with the increase in ( $\mathrm{NbTi}) \mathrm{C}$ content, from 498.9 MPa for steel A to $759 \mathrm{MPa}$ for steel C, with an increase of $52.1 \%$, and then slightly reduced to 736.6 MPa for steel D. Figure $7 \mathrm{~b}$ shows the Vickers hardness and Rockwell hardness of the test steels. With the increase in (NbTi)C content, the hardness demonstrated an increasing trend. Among them, the Vickers hardness increased from 213.3 HV for steel A to $306 \mathrm{HV}$ for steel D, with an increase of $43.5 \%$, and the Rockwell hardness increased from 14.7 HRC for steel A to $29.3 \mathrm{HRC}$ for steel D, with an increase of $100 \%$.

(a)

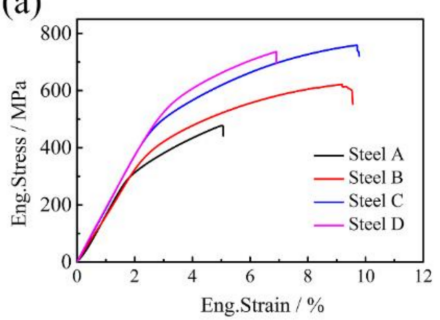

(b)

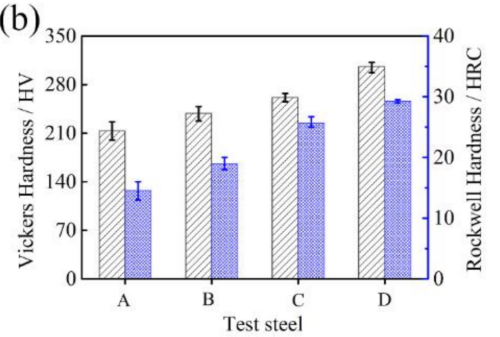

Figure 7. (a) Engineering strain-stress curve of the cast test steels; (b) Vickers and Rockwell hardness of cast steel with different $(\mathrm{NbTi}) \mathrm{C}$ additions.

\section{Discussion}

Regardless of whether the added particles strengthen magnesium alloys, aluminum alloys, or steel materials, it is generally believed that the addition of particles causes two main mechanisms for grain refinement, namely, increasing heterogeneous nucleation location and inhibiting grain growth [24,25]. In the smelting process studied in this paper, $(\mathrm{NbTi}) \mathrm{C}$ nanoparticles were dispersed in the melt, which ultimately led to significant changes in the solidification microstructure and refinement of the grain size. This is mainly because, on the one hand, $(\mathrm{NbTi}) \mathrm{C}$ nanoparticles can become the heterogeneous nucleation location of the $\gamma$ phase to refine the crystal grains; on the other hand, $(\mathrm{NbTi}) \mathrm{C}$ nanoparticles are repelled to the grain boundaries to inhibit the growth of grains. As a result, the prior austenite grains can also be refined, which ultimately leads to a significant decrease in the grain diameter (the average grain diameters of steel A and steel D were $16.3 \mu \mathrm{m} 10.0 \mu \mathrm{m}$, respectively, which is a $61.3 \%$ reduction), which is consistent with the previous research results [22]. While, in the course of the research, two kinds of particles containing $\mathrm{Nb}$ and Ti elements with different shapes from the added nanoparticles were observed, see Figures $4 \mathrm{a}$ and $5 \mathrm{a}$. Therefore, this article analyzes the reason for and the process of their formation.

The prepared $(\mathrm{NbTi}) \mathrm{C} / \mathrm{Fe}$ powder was added to cast steel to obtain modified steel. A part of (NbTi)C nanoparticles became the heterogeneous nucleation location of the $\gamma$ phase, mainly as a result of the three special properties of $(\mathrm{NbTi}) \mathrm{C}$ nanoparticles: (1) wetted in time; (2) a low degree of mismatch with the $\gamma$ phase; and (3) the surface dissolves locally, forming constitutional overcooling. It is worth noting that because of the low concentration of $\mathrm{Nb}$ and $\mathrm{Ti}$ in the melt, the surface of the $(\mathrm{NbTi}) \mathrm{C}$ nanoparticles may melt, which results in a higher concentration of $\mathrm{Nb}$ and $\mathrm{Ti}$ elements around the $(\mathrm{NbTi}) \mathrm{C}$ nanoparticles. During the cooling process, constitutional overcooling occurred, so concentration fluctuations were formed in the vicinity of the nanoparticles, causing ( $\mathrm{NbTi}$ ) C nanoparticles to become the heterogeneous nucleation location. In the process, their size decreased and their morphology did not change (ellipsoid type, shown in Figure 4e).

$$
\lg ([\mathrm{Nb}][\mathrm{C}]) \gamma=2.96-7510 / \mathrm{T}
$$




$$
\lg ([\mathrm{Ti}][\mathrm{C}]) \gamma=2.75-7000 / \mathrm{T}
$$

According to the solubility formula [26,27], at $1473 \mathrm{~K}$, the solubility of $\mathrm{Nb}$ and $\mathrm{Ti}$ in the $\gamma$ phase is $0.02 \%$ for both, which is lower than the content of $\mathrm{Nb}$ and $\mathrm{Ti}$ in the molten steel. Therefore, $\mathrm{Nb}$ and Ti elements are precipitated in the austenite phase during the cooling process after smelting. The square $(\mathrm{NbTi}) \mathrm{C}$ (Figure $4 \mathrm{~b}$ ) may be the precipitated phase with a size of about $100 \mathrm{~nm}$. It is precisely due to the precipitation in the grain that causes the degradation of pearlite.

Another part of the added $(\mathrm{NbTi}) \mathrm{C}$ nanoparticles move with the solidification front in the liquid phase. After the $\delta$-Fe phase transition is completed, the peritectic phase transformation $\mathrm{L}+\delta \rightarrow \gamma$ occurs in the melt, which makes the content of $\mathrm{Nb}$ and Ti dissolved in the remaining liquid phase increase, and the eutectic phase transformation $\mathrm{L} \rightarrow \gamma+$ $(\mathrm{NbTi}) \mathrm{C}$ occurs in the remaining liquid.

$$
\begin{aligned}
& \lg ([\mathrm{Nb}][\mathrm{C}])_{\mathrm{L}}=4.988-9506 / \mathrm{T} \\
& \lg ([\mathrm{Ti}][\mathrm{C}])_{\mathrm{L}}=5.317-9393 / \mathrm{T}
\end{aligned}
$$

At $1873 \mathrm{~K}$, according to the solubility formula [28], the solubility of $\mathrm{Nb}$ and $\mathrm{Ti}$ in the liquid phase is $2.05 \%$ and $5.01 \%$, respectively, which is much higher than the actual content of $\mathrm{Nb}$ and $\mathrm{Ti}$ in steel. Therefore, the eutectic phase transformation may occur during the cooling process and form eutectic ( $\mathrm{NbTi}) \mathrm{C}$ microparticles (Figures $2 \mathrm{~d}$ and $5 \mathrm{a}$ ). The formation of eutectic $(\mathrm{NbTi}) \mathrm{C}$ particles consumes the $\mathrm{C}$ element, resulting in an increase in the volume fraction of ferrite in prior austenite grain boundary.

To better show the dissolution and precipitation behavior of $(\mathrm{NbTi}) \mathrm{C}$ nanoparticles in melt, Thermo-Calc software was used to simulate the solubility of $(\mathrm{NbTi}) \mathrm{C}$ in molten steel at different temperatures, as shown in Figure 6. Theoretically, in the equilibrium state, the added $(\mathrm{NbTi}) \mathrm{C}$ nanoparticles would be completely dissolved in the molten steel and would be precipitated by a large amount during the subsequent homogenization transformation $\left(1427.3^{\circ} \mathrm{C}\right)$, and the rest would be precipitated in the ferrite transformation stage. While in the course of experiment, because of the short liquid holding time (15 min), only some of $(\mathrm{NbTi}) \mathrm{C}$ nanoparticles were dissolved. In the solidification process, the eutectic transformation occurred in the remaining liquid phase and formed micrometer $(\mathrm{NbTi}) \mathrm{C}$ particles; in the high temperature stage of furnace cooling, the supersaturated $\mathrm{Nb}$ and Ti elements in grain were precipitated to form square (NbTi)C nanoparticles. In the low temperature stage of cooling, there was no precipitation as a result of the low diffusion coefficient.

In terms of mechanical properties, the tensile strength and elongation of the test steels increased first and then decreased with the increase in (NbTi)C nanoparticles. The increasing trend of elongation is consistent with that of the volume fraction of ferrite. It can be considered that the increase in ferrite is the main reason for the increase in plasticity of the modified steels. When the content was $0.16 \mathrm{wt} . \%$, the tensile strength and elongation reached maximum values, which were $759 \mathrm{MPa}$ and $5.73 \%$, respectively. Compared to those without addition, the growth rate was $52.1 \%$ and $94.2 \%$, respectively. The improvement of tensile strength was mainly due to the reduction in grain size (Figure 3) and the pinning effect of nanoparticles (Figure 4). When the content increased to $0.66 \mathrm{wt} . \%$, the tensile strength and elongation significantly decreased. This may be related to the formation of the eutectic $(\mathrm{NbTi}) \mathrm{C}$. During the plastic deformation of the test steels, the eutectic (NbTi)C tends to be the source of cracks, and cracks rapidly expand along the boundary of the eutectic $(\mathrm{NbTi}) \mathrm{C}$. As for the hardness, Vickers hardness and Rockwell hardness both demonstrated an increasing trend with the increase in the added amount. Compared to steel A, steel D increased by $43.0 \%$ and $100.0 \%$, respectively. On the one hand, the decrease in grain size increases the grain boundary and thus increases the resistance of the material to external deformation; on the other hand, the various forms of hard ( $\mathrm{NbTi}) \mathrm{C}$ particles provide a part of the hardness. 
In short, the addition of $(\mathrm{NbTi}) \mathrm{C}$ nanoparticles can greatly improve the material performance, but when the addition amounts are greater than a certain value, eutectic ( $\mathrm{NbTi}) \mathrm{C}$ particles will cause a deterioration in performance. In addition, in order to minimize the loss of $(\mathrm{NbTi}) \mathrm{C}$, the melting time and high temperature holding time should be minimized during the material preparation process.

\section{Conclusions}

By adding the (NbTi)C nanoparticles into cast 1045 steel, the modified steels with different contents were obtained. After the observation and analysis of the microstructure and the mechanical properties tests, the following conclusions were drawn:

1. The presence of the second phases in the cast steel, which are different from the added $(\mathrm{NbTi}) \mathrm{C}$ nanoparticles, is due to the dissolution and precipitation behavior of $(\mathrm{NbTi}) \mathrm{C}$ nanoparticles during the smelting process. Among them, the square nano$(\mathrm{NbTi}) \mathrm{C}$ with a size of about $100 \mathrm{~nm}$ are formed by intragranular precipitation, and the micro-( $\mathrm{NbTi}) \mathrm{C}$ is formed by the eutectic precipitation at the grain boundaries.

2. The addition of $(\mathrm{NbTi}) \mathrm{C}$ nanoparticles can refine the microstructure and improve the hardness and strength. The average grain diameter decreased from $16.3 \mu \mathrm{m}$ in steel A to $10.0 \mu \mathrm{m}$ in steel D; the tensile strength increased from $498.9 \mathrm{MPa}$ in steel A to $759.0 \mathrm{MPa}$ in steel $\mathrm{D}$, an increase of $52.1 \%$. A continued increase in $(\mathrm{NbTi}) \mathrm{C}$ will lead to a decrease in strength.

Author Contributions: Conceptualization, F.X. and H.Z.; methodology, H.Z. and H.L.; software, F.X., H.Z. and H.L.; validation, F.X. and H.Z.; formal analysis H.Z., F.X. and Z.G.; investigation, H.Z. and H.L.; writing—original draft preparation, H.L. and H.Z.; writing—review and editing, H.Z., F.X. and Z.G.; project administration, F.X.; funding acquisition, F.X. and H.Z. All authors have read and agreed to the published version of the manuscript.

Funding: This work was supported by the Natural Science Foundation of China (Grant NO. 51671164 and 51171162).

Institutional Review Board Statement: This study did not involve humans or animals. Please exclude this statement.

Informed Consent Statement: Not applicable.

Data Availability Statement: The raw/processed data required to reproduce these findings cannot be shared at this time because of time limitations.

Acknowledgments: Hongwei Zhu acknowledges the financial support of the doctoral teacher's research initiation grant project of Shanxi Datong University.

Conflicts of Interest: The authors declare that they have no conflict of interest.

\section{References}

1. Jia, Z;; Misra, R.D.K.; O'Malley, R.; Jansto, S.J. Fine-scal precipitation and mechanical properties of thin slab processed titaniumniobium bearing high strength steels. Mater. Sci. Eng. A 2011, 528, 7077-7083. [CrossRef]

2. Olalla, V.C.; Bliznuk, V.; Sanchez, N.; Thibaux, P.; Kestens, L.A.I.; Petrov, R.H. Analysis of the strengthening mechanisms in pipeline steels as a function of the hot rolling parameters. Mater. Sci. Eng. A 2014, 604, 46-56. [CrossRef]

3. Wang, J.; Yuan, W.; Mishra, R.S.; Charit, I. Microstructure and mechanical properties of friction stir welded oxide dispersion strengthened alloy. J. Nucl. Mater. 2013, 432, 274-280. [CrossRef]

4. El-Faramawy, H.S.; Ghali, S.N.; Eissa, M.M. Effect of Titanium addition on the behavior of medium carbon steel. J. Miner. Mater. Charact. Eng. 2012, 11, 1108-1112. [CrossRef]

5. Zhao, J.; Jiang, Z.; Lee, C.S. Enhancing impact fracture toughness and tensile properties of a microalloyed cast steel by hot forging and post-forging heat treatment process. Mater. Des. 2013, 47, 227-233. [CrossRef]

6. Han, Y.; Shi, J.; Xu, L.; Cao, W.Q.; Dong, H. TiC precipitation induced effect on microstructure and mechanical properties in low carbon medium manganese steel. Mater. Sci. Eng. A 2011, 530, 643-651. [CrossRef]

7. Luo, Z.C.; Ning, J.P.; Wang, J.; Zheng, K.H. Microstructure and wear properties of TiC-strengthened high-manganese steel matrix composites fabricated by hypereutectic solidification. Wear 2019, 432, 202970. [CrossRef] 
8. Lee, Y.H.; Ko, S.; Park, H.; Lee, D.; Shin, S.; Jo, I.; Lee, S.-B.; Lee, S.-K.; Kim, Y.; Cho, S. Effect of TiC particle size on high temperature oxidation behavior of TiC reinforced stainless steel. Appl. Surf. Sci. 2019, 480, 951-955. [CrossRef]

9. Gomes, U.U.; Oliveira, L.A.; Soares, S.R.S.; Furukava, M.; Souza, C.P. Effect of the dispersion of nanosized carbides (NbC-TaC) in the sintered microstructure of the stainless steel 316L. Mater. Sci. Forum 2008, 591-593, 294-298. [CrossRef]

10. Gülsoy, H.O. Production of injection moulded 316L stainless steels reinforced with TiC(N) particles. Mater. Sci. Technol. 2008, 24, 1484-1491. [CrossRef]

11. Qin, S.; Liao, B.; Mao, L.; Xiao, F. A novel method for preparing nano-NbC/Fe powder and nano-NbC particle reinforced cast low-carbon steel. Mater. Lett. 2014, 121, 162-165. [CrossRef]

12. Lazarova, R.; Petrov, R.H.; Gaydarova, V.; Davidkov, A.; Alexeev, A.; Manchev, M.; Manolov, V. Microstructure and mechanical properties of P265GH cast steel after modification with TiCN particles. Mater. Des. 2011, 32, 2734-2741. [CrossRef]

13. Qin, S.; Liao, B.; Xiao, F.; Mao, L. Fabrication of $\mathrm{NbC}$ reinforced low carbon steel by immersing $\mathrm{Nb}(\mathrm{C})$-Fe powders in steel melt. Mater. Manuf. Process. 2015, 30, 116-121. [CrossRef]

14. Lazarova, R.; Bojanova, N.; Dimitrova, R.; Panov, I.; Manolov, V. Influence of nanoparticles introducing in the melt of aluminum alloys on castings microstructure and properties. Int. J. Metalcast. 2016, 10, 466-476. [CrossRef]

15. Sang-Hoon, L.E.E.; Jin-Ju, P.A.R.K.; Sung-Mo, H.O.N.G.; Byoung-Sun, H.A.N.; Min-Ku, L.E.E.; Chang-Kyu, R.H.E.E. Fabrication of cast carbon steel with ultrafine TiC particles. Trans. Nonferr. Metals Soc. China 2011, 21, 54-57.

16. Park, J.J.; Hong, S.M.; Park, E.K.; Kim, K.Y.; Lee, M.K.; Rhee, C.K. Microstructure and properties of SA 106B carbon steel after treatment of the melt with nano-sized TiC particles. Mater. Sci. Eng. A 2014, 613, 217-223. [CrossRef]

17. Hong, S.M.; Park, E.K.; Park, J.J.; Lee, M.K.; Lee, J.G. Effect of nano-sized TiC particle addition on microstructure and mechanical properties of SA-106B carbon steel. Mater. Sci. Eng. A 2015, 643, 37-46. [CrossRef]

18. Hong, S.M.; Park, J.J.; Park, E.K.; Lee, M.K.; Rhee, C.K.; Lee, J.K. Cavitation erosion behavior of SA 106B carbon steel after treatment of the melt with nano-sized TiC particles. Tribol. Int. 2015, 92, 585-594. [CrossRef]

19. Park, J.J.; Park, E.K.; Lee, G.J.; Rhee, C.K.; Lee, M.K. Effect of a nano-sized TiC particle addition on the flow-assisted corrosion resistance of SA 106B carbon steel. Appl. Surf. Sci. 2017, 415, 143-148. [CrossRef]

20. Podgornik, B.; Torkar, M.; Burja, J.; Godec, M.; Senčič, B. Improving properties of spring steel though nano-particles alloying. Mater. Sci. Eng. A 2015, 638, 183-189. [CrossRef]

21. Kim, J.M.; Park, J.S.; Yun, H.S. Microstructure and mechanical properties of TiC nanoparticle-reinforced iron-matrix composites. Strength Mater. 2014, 46, 177-182. [CrossRef]

22. Zhu, H.W.; Ke, W.J.; Zhao, Z.P.; Qin, S.; Xiao, F.R.; Liao, B. Refinement effectiveness of self-prepared (NbTi)C nanoparticles on as-cast 1045 steel. Mater. Des. 2018, 139, 531-540. [CrossRef]

23. Zhu, H.W.; Xu, K.; Qin, S.; Xiao, F.R.; Liao, B. Effect of heat treatment on microstructure and properties of 1045 steel modified with (NbTi)C nanoparticles. Mater. Sci. Eng. A 2018, 728, 175-182. [CrossRef]

24. Rajabi, A.; Ghazali, M.J.; Daud, A.R. Chemical composition, microstructure and sintering temperature modifications on mechanical properties of TiC-based cermet-A review. Mater. Des. 2015, 67, 95-106. [CrossRef]

25. Chen, X.; Qiu, L.; Tang, H.; Luo, X.; Zuo, L.; Wang, Z.; Wang, Y. Effect of nanoparticles formed in liquid melt on microstructure and mechanical property of high strength naval steel. J. Mater. Process. Technol. 2015, 222, 224-233. [CrossRef]

26. Nordberg, H.; Aronsson, B. Solubility of Niobium Carbide in Austenite. Available online: https://www.researchgate.net/ publication/284059865_Solubility_of_niobium_carbide_in_austenite (accessed on 29 November 2020).

27. Irvine, K.J.; Pickering, F.B.; Gladman, T. Grain Refined C-Mn Steels. Available online: https://www.researchgate.net/publication/ 301327997_Grain-refined_C-Mn_steels (accessed on 29 November 2020).

28. Chen, J.X. Manual of Chart and Data in Common Use of Steel Making; Metallurgical Industry Press: Beijing, China, 1984. [CrossRef] 